\title{
Possibilities of modern software complexes in simulation fire protection of constructions structures with Sofistik
}

\author{
Marina Gravit ${ }^{1}$, Vladimir Lyulikov ${ }^{1,{ }^{*}}$ and Alina Fatkullina ${ }^{2}$ \\ ${ }^{1}$ Peter the Great St. Petersburg Polytechnic University, 29 Politechnicheskaya St., 195251, St. \\ Petersburg, Russia \\ ${ }^{2}$ Moscow State University of Civil Engineering, Yaroslavskoe shosse, 26, 129337, Moscow, Russia
}

\begin{abstract}
The review of modern software systems that allow producing modeling and calculation of fire resistance of building structures, as well as simulating fire protection, is given. Particular attention is paid to the software Sofistik, which allows you to synchronize with Autodesk Revit and calculate the fire protection of building structures for various temperature regimes.
\end{abstract}

\section{Introduction}

Due to the increase in the number of fires and other emergencies that may be the cause of the fire or are their consequence, the actual task is to improve the methods for calculating the fire resistance of structures, including taking into account fire protection.

One of the most pressing issues is the provision of fire resistance and fire protection of iron-concrete structures [1-5]. In the Russian Federation, for the calculation of the composite steel structure for fire exposure, use STO 36554501-006-2006 [6]. In the European countries there is a technical code Eurocode- 4 and institutions involved in the design of structures, publish a number of recommendations on the calculation $[7,8]$. For the calculation of metal and wood structures in Europe, the corresponding Eurocodes are used, in Russia, manufacturers develop their own software.

At present, software complexes are widely used in civil engineering, in which there are modules for calculating fire resistance, for example, Sofistik (Germany), ABAQUS (USA), Normcad (Russia), Ansys (USA) and Robot structure (USA), Elcut (Russia), etc., which allow to calculate the distribution of temperature fields in a structure in time, without loading and with its account (the fire resistance limit of structures) under conditions of a special fire load. Each security has different capabilities, advantages and disadvantages. Among the criteria, the most important, apart from the accuracy of the calculation, are the flexibility and intuition of the interface, the ability to export the finished model from Autodesk Revit, the function of forming a custom cross-section, the presence of various fire regimes, an automatic report on technical and visual characteristics, etc. ${ }^{*}$

\footnotetext{
*Corresponding author: lulikv@yandex.ru
} 


\section{Methods}

The essence of the methods consists in determining the time from the beginning of the thermal action on the structure before one or several successive states of fire resistance occur, taking into account the functional design purpose. In each of the modern software systems, the finite element method is used as the basic calculation method.

As a rule, the calculations obtained in different software complexes have the same technical result, but the reports on the solved problem are designed in a unique way for each developer: in some cases, the user is provided with a ready-made document, issued according to standards for examination, and in a similar software package from another manufacturer, the output of the results can look quite different. Figure 1 shows a fragment of the report in the "Sofistik" software suite, where the user can visually assess the impact on a given design. Figure 2 presents the graphical interface of the fire resistance module in Sofistik. Sofistik modules cover 3 sections: data entry and generation of calculation schemes, calculation, analysis of results. All project data is managed using a common database. Thus, flexible data exchange is possible with different input methods and optimal interfaces for combining in one CE model.

After export, the model is rendered in a finite-element form and automatically suggests calculating the cross-sections of the specified elements. Calculation of fire resistance with the HYDRA module is carried out only for individual elements. If it is necessary to calculate the fire resistance of the entire structure, the ASE module is used, for which the temperature load is pre-set (it is set, as a rule, in the preprocessor SofiPLUS AutoCad)
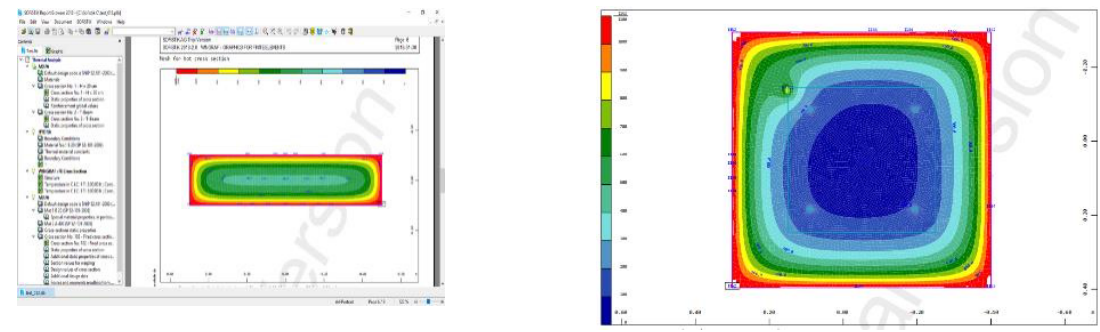

Fig. 1. Type of heating of the structure of the floor and section of the reinforced concrete column in the report "Sofistik".

The market of software complexes for calculating fire resistance extensively applies calculations for reinforced concrete structures, for steel and wood structures, especially with fire protection, the situation is much more difficult - only a few programs have such applications, not to mention the choice of different fire regimes (standard, outdoor, hydrocarbon, smoldering). There is a common interest of developers in the creation of products for automated design and calculation of the limits of fire resistance of various structures under loading conditions. 


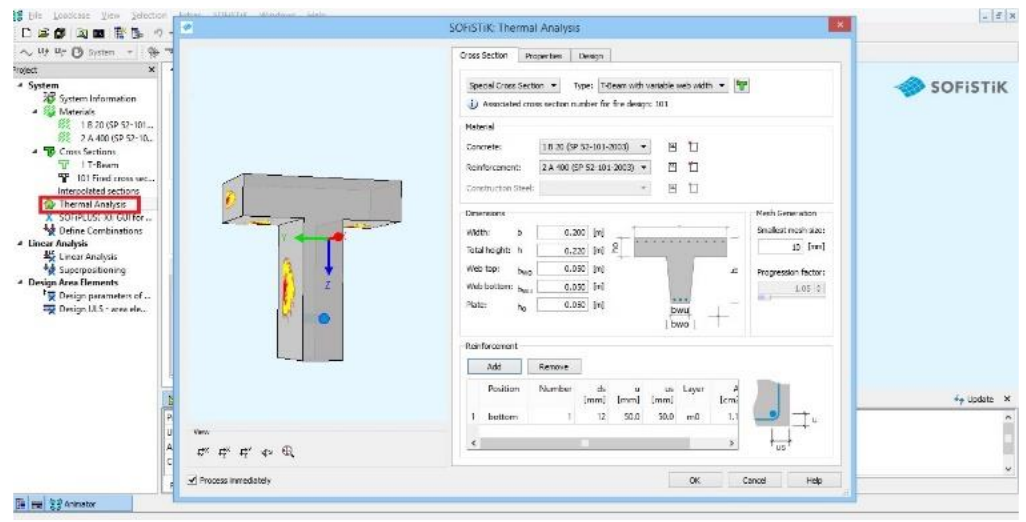

Fig. 2. Graphic interface of the fire resistance module in Sofistik.

\section{Results and Discussion}

In Sofistik there is an opportunity not only to set the required load and the maximum fireresistance time, but also to choose different temperature regimes of the fire. Especially relevant are such calculations for the construction of buildings and structures in the oil and gas industry. In Fig. 3 is a view of the heating of the I-section of the I-pillar, which is affected by both the standard and hydrocarbon fire conditions. Geometrical dimensions of the column $600 \times 600$, load $10 \mathrm{kN}$. As a result, the program considers the different heating rates for the constructions according to different curves according to the standard EN 1363-2: 1999 "Fire resistance tests - Part 2: Alternative and additional procedures" for a fire resistance limit of 120 minutes.
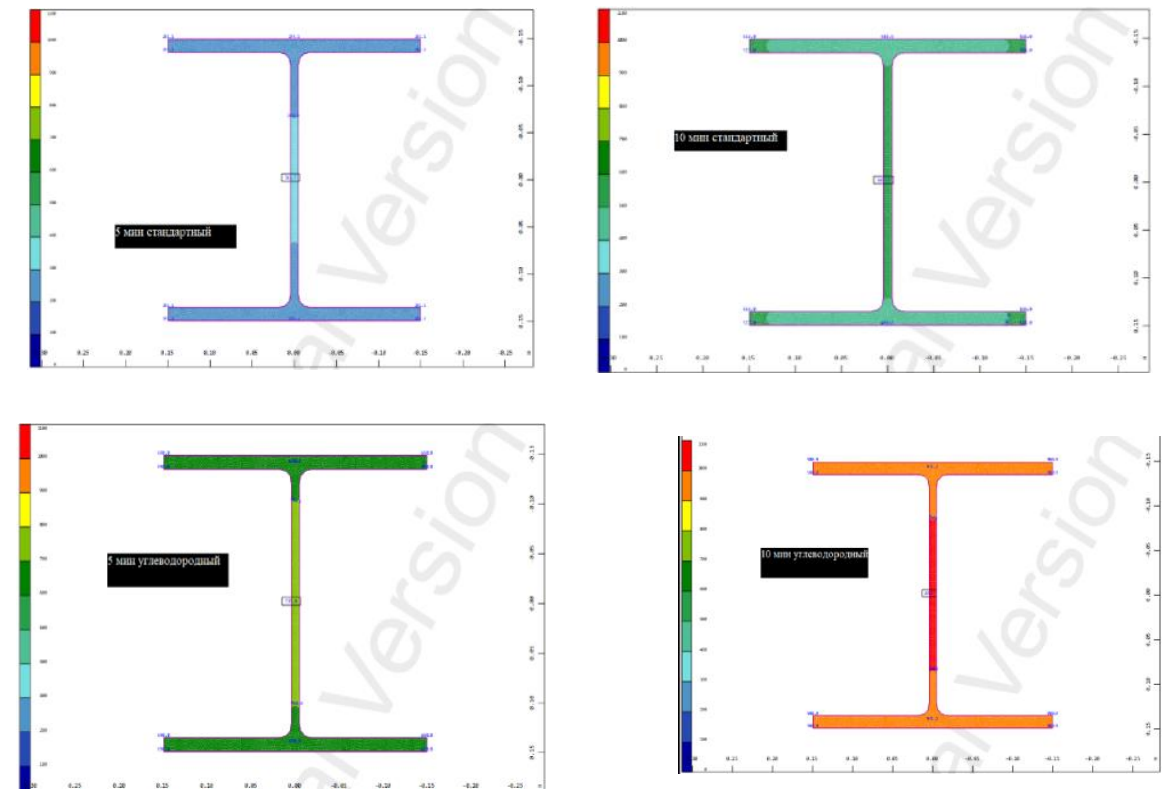

Fig. 3. Type of heating of I-section under different temperature conditions of fire. Left - 5 minutes, right - 10 minutes. At the top - the standard fire mode, at the bottom - the hydrocarbon fire mode. 
In the case where fire protection is required, the user specifies the cross-section and selects the type of fire protection according to the thermal and technical parameters for the construction material. For example, for a given I-bar under conditions of a hydrocarbon fire regime, cement plaster was selected (Fig. 4).

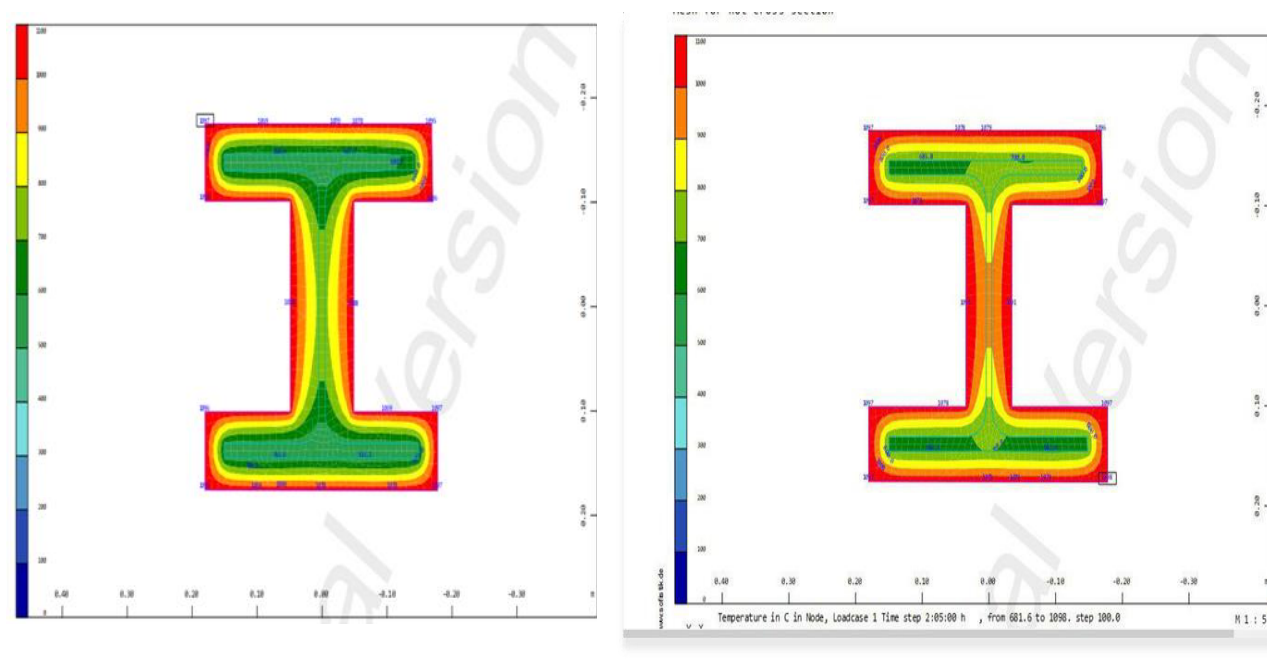

Fig. 4. Calculation of heating of I-section under fire protection plaster solution min at $125-800 \mathrm{C}$ in the center of an I-beam. The critical temperature is 710 and $707^{\circ} \mathrm{C}$ for the 1 st and 2 nd samples.

\section{Conclusions}

With the development of modern numerical methods, in some cases it is advisable to replace expensive field tests of fire resistance with computer simulation of the behavior of structures in a fire. The accuracy of modern software systems is comparable to actual tests, and accounting for various fire factors can guarantee a high degree of proximity to real situations. Among the modern software there are a sufficient number of alternatives for calculating the fire resistance of both individual elements and entire structures. The choice of a program primarily depends on the complexity of the user task. The cost of the PC varies proportionally to the functionality incorporated in them. An unambiguous leader in the possibilities of calculations is Ansys, which has a huge number of functions and tools for modeling fullfledged buildings and simulating a fire in a given location. However, in a number of cases, the modeling of entire structures does not have practical and economic feasibility, therefore, taking into account the cost of programs and the opportunities they provide, it can be argued that the most optimal choice, in the opinion of the authors, is Sofistik

\section{References}

1. A. Krivtcov, M. Gravit, S. Zimin, O. Nedryshkin, V. Pershakov, Matec Web of Conferences, 23-27 (2016)

2. A.V. Ulybin, Magazine of Civil Engineering 1(27), 4-13 (2012)

3. SRT 36554501-006-2006, Rules for ensuring fire resistance and fire safety of reinforced concrete structures

4. EN 1994-2-2009 (02250) Eurocode 4. Design of reinforced concrete structures 
5. M.O. Dudin, N.I. Vatin, Y.G. Barabanshchikov, Magazine of Civil Engineering 54(2), 33-45 (2015)

6. M. Salminen, M. Heinisuo, Journal of Constructional Steel Research 97, 105-113 (2014)

7. P. Kraus, M. Mensingera, F. Tabelingb, P. Schaumann, Structural Fire Engineering 6(4), 237-246 (2015)

8. M. Salminen, M. Heinisuo, Journal of Constructional Steel Research 97, 105-113 (2014) 